Pre-print of: Sánchez, A. "A kinetic analysis of solid waste composting at optimal conditions" in Waste management (Ed. Elsevier), vol. 27, issue 6 (2007), p. 854-855. The final version is available at DOI 10.1016/j.wasman.2004.12.021

\title{
Discussion
}

\section{A kinetic analysis of solid waste composting at optimal conditions *}

Antoni Sánchez **

Chemical Engineering Department

Escola Tècnica Superior d'Enginyeria

Universitat Autònoma de Barcelona

Bellaterra (Cerdanyola del Vallès, 08193-Barcelona, Spain)

* Originally published in: Komilis, D.P., Waste Management, 26 (2006), 82-91.

** Corresponding author: Antoni Sánchez. Tel.: 34-935811019, Fax: 34-935812013, E-mail address:

antoni.sanchez@uab.cat 


\begin{abstract}
This discussion explores the possibility of having a measure of the biodegradable organic carbon content in solid wastes. Today, indirect measures for the determination of biodegradable organic matter are being used and most of them are based on respiration indices (oxygen consumption or carbon dioxide production) or chemical parameters (volatile solids or total organic carbon). The results obtained for the cumulative carbon dioxide production in composting experiments can be expressed as "aerobic biodegradable carbon" for the wastes studied. The calculation of a useful biodegradable $\mathrm{C} / \mathrm{N}$ ratio can be also obtained from the aerobic biodegradable carbon content. The comparison with some results obtained in the measure of "anaerobic biodegradable carbon" is also presented.
\end{abstract}

\title{
Discussion
}

The recent work by Komilis on the kinetics analysis of solid waste composting present some results that can be of interest for the composting research community. In the paper, different solid wastes are composted and the total cumulative production of carbon dioxide is determined. Since the experiment is considered finished when the $\mathrm{CO}_{2}$ production is not significant (except for grass, which is not considered in this discussion), this means that biodegradable organic matter is exhausted and that the carbon released in form of carbon dioxide is representative of the biodegradable organic carbon content in the original waste. Table 4 shows the calculation of this content referred to the initial content of total organic carbon from data of Komilis. To our knowledge, this is the first reference to an approximation of a direct determination of the biodegradable organic carbon in a solid waste, since indirect measures or chemical parameters are currently used.

Some interesting aspects can be analyzed in Table 4. Initial organic carbon (as it is chemically measured) does not present significant differences for the organic wastes studied. However, biodegradable organic carbon is very different from waste to waste, as it is usually observed in the composting experiments of these wastes. This measure permits to classify wastes in a biodegradability/compostabilty scale, being food wastes, as expected, the most biodegradable/compostable waste. Other wastes with a high content of lignin (such as branches) 
present a low biodegradability. On the other hand, if biodegradable carbon is known, the biodegradable $\mathrm{C} / \mathrm{N}$ ratio can be estimated assuming that most of the nitrogen is biodegradable, since nitrogen is mainly found in solid wastes in form of protein. The biodegradable (real) $\mathrm{C} / \mathrm{N}$ ratios are also presented in Table 4. As expected, the values are lower than the total $\mathrm{C} / \mathrm{N}$, which is based on a total $\mathrm{C}$ determination. The biodegradable $\mathrm{C} / \mathrm{N}$ ratio can be then very useful as a basis for the formulation of balanced mixtures of wastes in co-composting experiments with the objective of minimizing ammonia emissions and the maximum nitrogen preservation in the final compost.

Finally, it must be pointed that the biodegradable organic carbon obtained in controlled composting experiments should be considered as "aerobic biodegradable organic carbon". Our research group has some experience in the determination of cumulative biogas production in solid wastes under anaerobic conditions. As biogas produced is determined in these experiments and the percentages of methane and carbon dioxide in biogas are know, the final cumulative production of CBiogas can be calculated and can be considered as a measure of "anaerobic biodegradable organic carbon". This is of special interest since it can permit the comparison with aerobic biodegradable organic carbon. The estimation of anaerobic biodegradable organic carbon with Spanish food wastes results in a $45 \%$ of C-biogas produced/initial carbon. Apart from the inherent utility of this value in the industrial anaerobic digestion of this waste, the comparison with the values reported by Komilis (74\% of $\mathrm{C}-\mathrm{CO}_{2}$ released/initial carbon) demonstrates that the amount of organic carbon to be aerobically degraded is significantly higher than the anaerobic biodegradable fraction.

In conclusion, the determination of biodegradable organic carbon (both aerobic and anaerobic) can be very useful for the biological organic waste treatment, especially in the balance of carbon and nitrogen in the composting process, and the design of optimized operations. 
Table 4: Biodegradable organic carbon in the wastes studied.

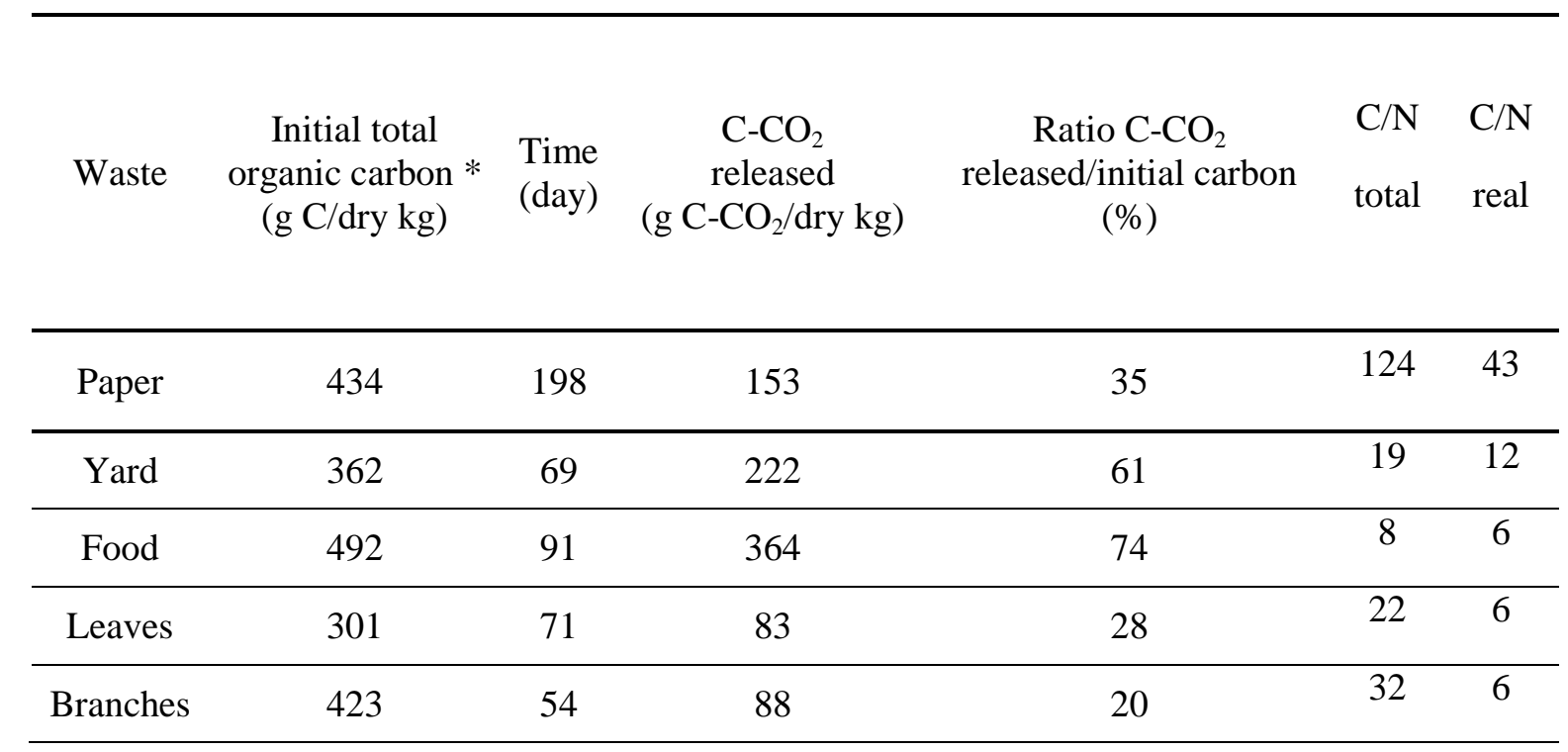

* Considering carbon from seed 